\title{
Kronik
}

juli - september 1996

\section{Det nationale Fotomuseum}

Det kongelige Bibliotek oprettede den 20. september 1996 et museum for fotografiet som medieform og kunstart.

Dermed realiseres den første etape af et museumsprojekt, der har været mange år undervejs. Næste etape bliver åbning i egne lokaler. Det vil ske i efteråret 1998, når Det kongelige Biblioteks store udvidelse ved havnefronten står færdigopført. Dér vil det kommende fotomuseum få udstillingsfaciliteter på ialt $437 \mathrm{kvm}$ til såvel særudstillinger som til udstillinger fra de permanente samlinger, ligesom der på 4. og 5. etage vil være en læsesal og tidssvarende magasinforhold.

Administrativt bliver fotomuseet en sektion i Kort- og Billedafdelingen under ledelse af kunsthistorikeren, førstebibliotekar, mag.art. Ingrid Fischer Jonge. Det bliver således også Kort- og Bil- ledafdelingens fotohistoriske samling, der vil komme til at danne grundstammen i det nye museum.

Den fotohistoriske samling regnes i dag blandt en af Europas fineste. Her findes William Henry Fox Talbots sjældne værk The Pencil of Nature fra 1844, der kun kendes i ganske få eksemplarer. Her findes det lige så sjældne værk Egypte, Nubie, Palestine et Syrie af Maxime du Camp fra 1852.

Desuden kan nævnes en større samling af Roger Fentons fotografier fra Krimkrigen i 1850 'erne og en samling fotografier af Edouard Baldus ligeledes fra 1850 'erne. Derudover kan nævnes værker af Julia Margaret Cameron, John Thomson, Edward Steichen, Wilhelm von Gloeden, August Sander, Erich Salomon, Albert Renger-Patzsch, Henri Cartier-Bresson, Bill Brandt, Richard Avedon, William Klein, Duane Michals, 


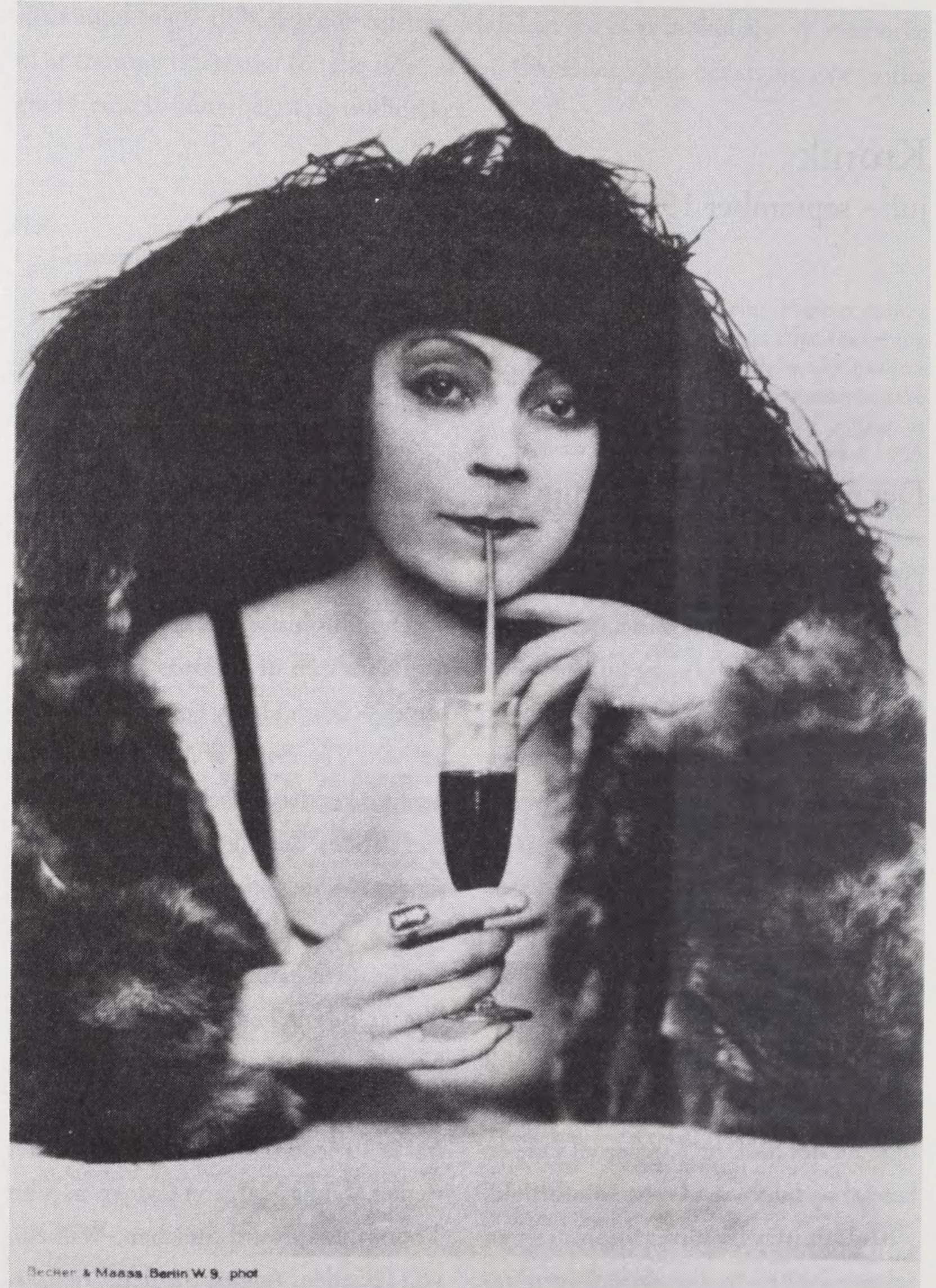

\section{Asta Nielsen}

Becker \& Maas: Asta Nielsen, ca. 1920. Postkortfotografi, 135 x 85 mm. Det kgl. Bibliotek. 


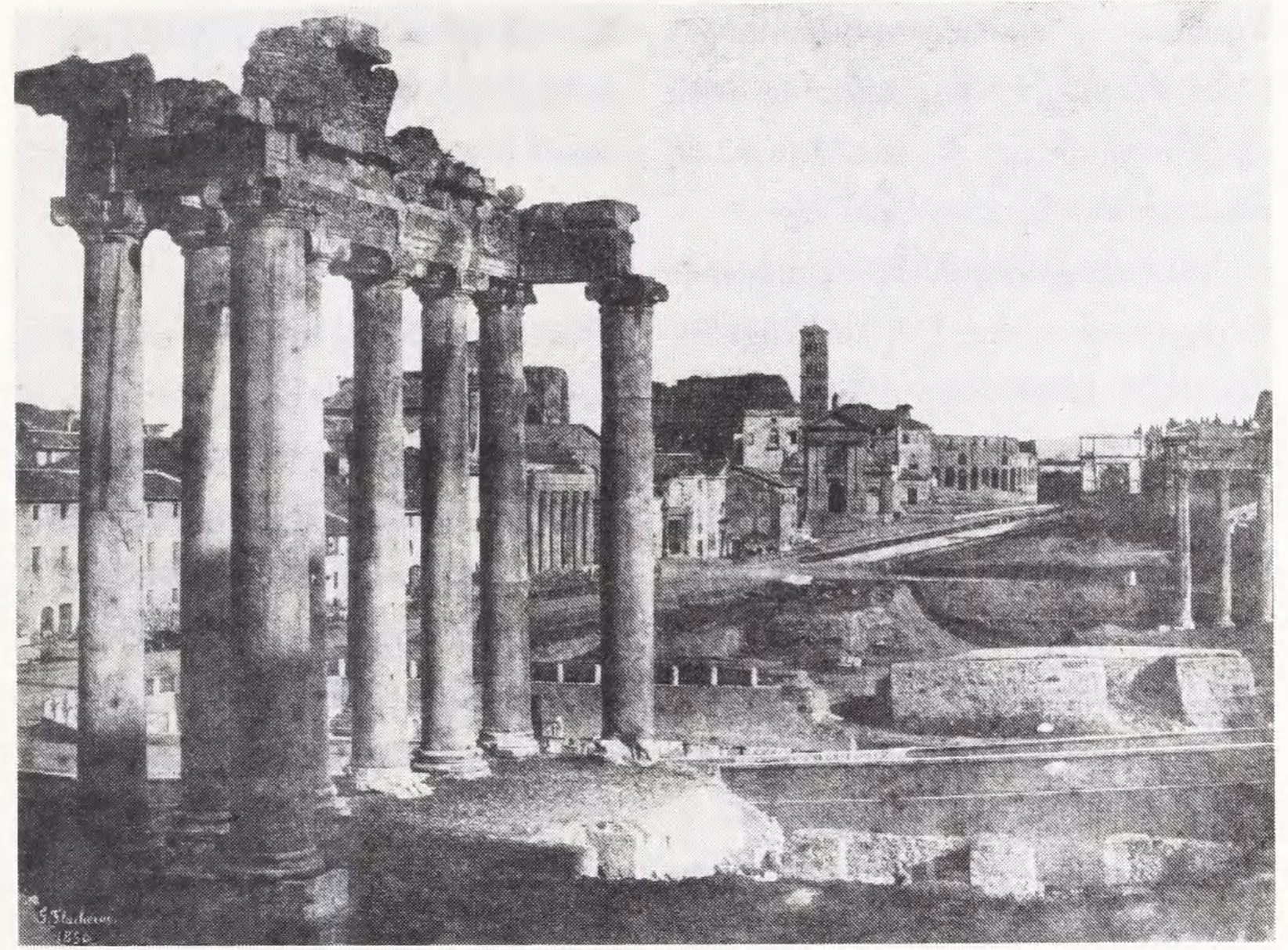

Frédéric Flachéron: Forum Romanum med Saturn templet. 1850. Kalotypi 246 x 332. Sign. og dat. nederst til venstre. Det kgl. Bibliotek.

Martin Parr, Paul Graham og Hirochige Sugimoto.

Samlingen rummer også henved 600 danske daguerreotypier ligesom dansk fotografi generelt er stærkt repræsenteret fra fotografiets første år frem til i dag.

Det var oprindelig Kort- og Billedafdelingens tidligere leder, førstebibliotekar Bjørn Ochsner, der i sin ansættelse fra 1944 til 1980 skabte afdelingens kolossale fotosamling, der udover den fotohistoriske samling er indeholdt $\mathrm{i}$ et emneregistreret billedarkiv, en portræt- samling, en negativsamling og en luftfotosamling. Det var ligeledes Bjørn Ochsner, der indledte diskussionen om oprettelsen af et fotomuseum. Det resulterede i, at Kulturministeriet i 1982 nedsatte en arbejdsgruppe med repræsentanter fra Statens Museum for Kunst, Nationalmuseet, Københavns Bymuseum, Det kongelige Bibliotek og fra fotografernes egne rækker. En midtvejsrapport blev afleveret samme år og $\mathrm{i}$ 1984 kunne gruppen afslutte sit arbejde med et tillæg.

Gruppen anbefalede oprettelsen af et 
fotomuseum, og Kulturministeriet gav ideen sin principielle tilslutning. Men alligevel skulle der gå yderligere 12 år, før der kom til at ske mere i sagen.

Ved navngivningen af det kommende fotomuseum ønsker Det kongelige Bibliotek at formalisere de mangeårige planer. De museale forberedelser er allerede påbegyndt med omorganisering og registrering af samlingen, med oprettelsen af et dokumentationsarkiv og med udstillingsplanlægningen.

Med udgangspunkt i samlingens karakter vil udstillingskonceptet omfatte det klassiske fotografi, såvel det historiske som det moderne og samtidsfotografiet. Det kommende fotomuseum vil således indgå i det københavnske udstillingsliv med fokus på den fotografiske udtryksmåde, og den fotografiske forskning vil samtidig få et sted, hvor relevant forskningsmateriale har sin naturlige plads.

Til navngivningen af det ny museum blev der lavet en lille udstilling af de mange gaver, det kommende museum med stor glæde allerede har modtaget.

Blandt gaveyderne skal nævines den svenske fotograf Georg Oddner, de danske fotografer Nana Bisp Büchert, Ole Christiansen, Krass Clement, Terry Colonel, Klaus Holsting, Tove Kurtzweil, Tage Poulsen, Viggo Rivad og Lars Schwander.
Endelig ønskede Nationalmuseet at bidrage til lejligheden med en tidsubestemt deponering af landskabsfotografen Sigvart Werners store fotoarkiv.

Som et led i festligholdelsen udgav Det kongelige Bibliotek bogen Fotografi på tryk, Essays og artikler af Bjørn Ochsner. Udvalg og indledning ved Ingrid Fischer Jonge. 172 sider ill. s/h. pris kr. 125 .

I udvalget præsenterer Bjørn Ochsner resultatet af sin forskning. Her fås klar besked og præcise informationer om en række forhold på den fotografiske scene i mediets unge år.

\section{Foredrag}

I tilknytning til Kulturby-udstillingen Kobenhavn - porten til Europa, som var arrangeret af Det kongelige Bibliotek, Rigsarkivet og Tøjhusmuseet, afholdtes i efteråret 1996 fem foredrag:

Museumsinspektør Kay Søren Nielsen, Tøjhusmuseet, talte 10. sept. om Damer og heste! Den unge enevalde - om Christian V.

Forskningsbibliotekar, eniorforsker ved Det kongelige Bibliotek Henrik Horstbølls foredrag 17. sept. hed Enevaldens maskerade - reform, revolution og enevalde i 1700-tallets Ko-benhavn.

Arkivar Margit Mogensen, Rigsar- 
kivet, havde 24. sept. Kvinder i sigte, og forskningsbibliotekar Erik Skyum-Nielsen, Det kongelige Bibliotek, talte 1. okt. om Dannelsesrejsens anatomi.

Sidste foredrag fandt sted 8. okt., hvor lektor Mogens Rüdiger, Handelshøjskolen, talte Om at flytte hegnspale i det danske demokrati.

Foredragene, der var gratis, fandt sted i Provianthuset.

\section{Udlån til udstillinger}

Kunst \& Videnskab, Københavns Universitet, 5.7.-11.8.96. Lån fra Danske Afdeling, Håndskriftafdelingen, Universitetsbiblioteksafdelingen.

Amalie Skram 150 år, Bergen Off. Bibliotek, aug. 1996-. Lån fra Håndskriftafdelingen.

Vesthimmerlands Museum, 6.9.6.10.96. Lån fra Danske Afdeling.

Ole Rømer Museet, 1.10.-30.11.96. Lån fra Danske Afdeling.

\section{Erhvervelser}

Danske Afdeling

Fra Ella Bechgaards dødsbo har Danske Afdeling modtaget hendes bogsamling som testamentarisk gave.
Håndskriftafdelingen

Maleren Cæsar Kunwalds efterladte breve, tegninger m.m.

En samling breve og tryksager vedrørende Dansk Pressetjeneste i Stockholm 1945.

En lille korrespondance mellem $\mathrm{R}$. Paulli og bogtrykker Volmer Nordlunde (især om Fund og Forskning).

En samling breve til præsten Samuel Wulff.

En lille samling manuskripter fra forfatteren Aage Barfoed.

En samling kunstnerbreve til kunstog littteraturhistorikeren Sigurd Müller.

Komponisten Finn Høffdings efterladte papirer. Musikmanuskripter overført til Musikafdelingen.

En samling breve til kommandør Otto Irminger fra blandt andre Knud Rasmussen, Fridtjof Nansen og MyliusErichsen.

Iøvrigt har afdelingen erhvervet en række andre samlinger og enkelte breve og manuskripter fra blandt andre Carit Etlar, Anna Bloch, Bjarne Thorarensen, Svend Dahl, Ole Wivel, Poul Schierbeck, Kaj Walther.

Opmærksomheden henledes på, at nogle af nyerhvervelserne af forskellige årsager må holdes utilgængelige indtil videre. 
Kort- og Billedafdelingen

Et portræt af Hans Bregenhøj (19131978) tegnet 1964 af Hans Bendix. Fra arkivar Carsten Bregenhøj.

En samling fotografier fra et defekt album, fotograferet af Peter Pontoppidan (1858-1930), der var inspektør ved fællessukkerkogerierne, Sct. Croix. Fra fru Inge Merete Blom, via Dansk Folkemindesamling.

En større samling danske og udenlandske portrætter m.v. med relation til familierne Drewsen og Collin samt album med tegninger, udklip og samlemærker. Fra fr. Elga Collin via fr. Anette Christensen.

Frue Kirke, radering af Albert Jensen. Fra fru Elise Budde.

108 plakater, fortrinsvis cirkusplakater. Fra forfatteren Anders Enevig.

Et tidligt håndkoloreret fotografi, oprindelig hidrørende fra Teknologisk Instituts fotografiske fagskole. Fra redaktør Flemming Berendt, Dansk Fotohistorisk Selskab.

1 fotografi af Martin Parr The last resort 1984/85.

7 fotografier fra Apostelserien fotograferet 1992 af Henrik Brahe.

3 fotografier af folketyper fra Sicilien fotograferet ca. 1900 af baron Wilhelm von Gloeden.

6 fotografier, serien I build a pyramid, fotograferet 1978 af Duane Michals.

2 fotogravurer udført 1995 af Lewis Baltz trykt hos Niels Borch Jensen, Værksted for kobbertryk, København.

Endvidere fotografier taget af blandt andre følgende fotografer: Nicolai Howalt, Anders Kjærgaard, Sten Lange, Stuart McIntyre, Per og Jon/Station 1, Michael Staggemeier, Petri Virtanen.

Som donation har afdelingen modtaget:

3 fotografier fra serien Medens langsomt tiden dor, fotograferet 1996 af Nanna Bisp Büchert.

Modefoto (Tilma) fotograferet 1966/ 67 af Ole Bjørk.

Henrik Brahe, serien Sankt Hans aften, København 1990.

6 fotografier, portrætter af Michael Kvium 1992/1996, Ole Bornedal 1994/ 1996, Peter Bech Sørensen 1989/1996, Jon Nordstrøm 1992/1996, Jacob 1989/ 1996, Morten Friis 1989/1996, fotograferet af Ole Christiansen.

2 fotografier fra Københavns Hovedbanegård 1969 og fra København 1978 fotograferet af Krass Clement.

2 landskabsfotografier, fotograferet af Fie Johansen 1996.

3 fotografier fra serien Det sansede Kobenhavn, fotograferet 1995 af Tove Kurtzweil.

2 portrætter fotograferet af Lars 
Schwander: Lewis Baltz 1995, Cindy Sherman 1995.

En samling portrætter og modefotos m.v. fotograferet af Torben Thesander, fortrinsvis 1970 'erne.

\section{Musikafdelingen}

I slutningen af december $1996 \mathrm{blev}$ det klart at det var lykkedes Kulturværdiudvalget efter adskillige års forhandlinger at skaffe de fornødne midler til at effektuere et udførselsforbud af arkivet efter Wilhelm Hansens Musikforlag, omfattende forlagsarkivalier, breve samt mere end 1.200 musikmanuskripter, som efterfølgende er blevet overdraget Det kongelige Bibliotek.

Wilhelm Hansens Musikforlag, grundlagt i 1854, opkøbte i de følgende årtier efterhånden de fleste daværende danske musikforlag og etablerede yderligere søsterforlag i Norge, Sverige og Tyskland, og opnåede nærmest monopol på nodeforlagsvirksomhed i Danmark. Arkivet indeholder således breve og musikmanuskripter vedrørende en lang række betydelige nordiske komponister fra det 19. og 20. århundrede og vil i fremtiden udgøre en væsentlig kilde til studiet af den nordiske musikhistorie i de sidste ca. 100 år i almindelighed og en enkelt betydningsfuld institution $i$ dansk musikkultur i særdeleshed.
Blandt de 1.231 musikmanuskripter, hvoraf den overvejende del er autografer, skal i denne sammenhæng fremhæves værker af N.W. Gade (bl.a. det utrykte korværk Gefion), Edvard Grieg (Holbergiana, 1884 og musik til Ibsens Peer Gynt), I.P.E. Hartmann (en række romancer og sange), Carl Nielsen (musik til skuespillet Moderen og Tyve folkelige Melodier) Knudåge Riisager (Ouverturen til Erasmus Montanus og Slaraffenland), Johann Svendsen (diverse skitsebøger) samt August Winding (sange og klaverstykker).

I løbet af den kommende tid vil musiksamlingen blive ordnet og katalogiseret, hvorefter den vil blive stillet til rådighed for musikforskningen, senest samtidig med åbningen af Center for Musik i Diamanten på Slotsholmen.

Fra cand.phil. Vivi Kjær er modtaget en omfattende privat samling grammofonplader (ialt 7.000 plader, heraf ca. halvdelen 78-plader) der gennem de sidste 40 år er indsamlet og registreret af afdøde overassistent i Københavns Magistrat Allan Hansen. Pladerne vil indgå i Musikafdelingens samling af fonogrammer, som er under opbygning med henblik på det nye Center for Musik i Diamanten.

Autograferne til Carl Nielsens tostemmige sang $O$, hvor er jeg glad $i$ Dag 
og Hermann D. Koppels Pastorale for Klaver samt originaludgaver af Friedrich Kuhlaus fløjteduo'er.

\section{Besøg}

Besøg 19. aug. 1996 af førstebibliotekar Lone Hansen, bibliotekar Leif Andersen og bibliotekar Hanne Kværndrup fra Statens Bibliotekstjeneste. Fra Det kongelige Bibliotek deltog direktør Erland Kolding Nielsen, overbibliotekarerne Karl Krarup og Steen Bille Larsen og administrationschef Bodil Henriksen.

Besøg 19. sept. 1996 af Biblioteksforeningen for Storkøbenhavn. Foredrag af direktør Erland Kolding Nielsen om Havnbefrontsbyggeriet.

Danske Afdeling har i september haft besøg af Klaus Georg Hansen, der er leder af Groenlandica ved Nationalbiblioteket i Nuuk, og Steingrimur Jonsson, der er leder af Svenska Afdelningen ved Lunds Universitetsbibliotek.

Direktør Regis Durand, Centre National de la Photogaphie, Paris, besøgte Kort- og Billedafdelingen 16. aug. 1996.

Bibliotekarerne Trissan Hansson og Margaretha Månsson fra Malmø Stadsbibliotek besøgte 29. juli 1996 Udlånsafdelingen. Formålet var dels at få et nærmere kendskab til Det kongelige Bibliotek, som Malmø Stadsbibliotek låner meget fra, og dels at besigtige Udlånsafdelingens indlån-funktion.

\section{Personalia}

Museumsinspektør, mag.art. Else Asmussen er 1. sept. 1996 - 31. aug. 1998 ansat som forskningsbibliotekar i arkæologi ved Universitetsbiblioteksafdelingen.

Lic.polit. Jørgen Ravn Elkjær er 1. aug. 1996 ansat som forskningsbibliotekar (seniorforsker) i nationaløkonomi ved Informations- og Dokumentationsafdelingen.

Førstebibliotekar Ingrid Fischer Jonge deltog 10.-11. sept. 1996 i FDK's (Foreningen af Danske Kunstmuseers) årsmøde i Randers.

Forskningsbibliotekar Henrik Horstbøll holdt 17. sept. 1996 foredraget Enevaldens maskerade - reform, revolution og enevalde $i$ 1700-tallets Kobenhavn som et led i samarbejdet mellem Det kongelige Bibliotek, Tøjhusmuseet og Rigsarkivet om Kulturby 96-udstillingen Kobenhavn - Porten til Europa.

Førstebibliotekar, dr.phil. Grethe Jacobsen holdt foredrag om Magt, stat og kon $i$ middelalder og reformationstid ved det 5. nordiske kvindehistorikermøde, Hønefoss, Norge, 8.-11. aug. 1996.

Forskningsbibliotekar (redaktør) Pe- 
ter Hauge var i sept. 1996 'referee' for det belgiske statsministerium SSTC (Service du premier ministre, affaires scientifiques, techniques et culturelles) vedrørende evaluering af et musikvidenskabeligt projekt.

Førstebibliotekar Ulf Haxen deltog 15.-23. juli 1996 i kollokvium samt planlægningsmøde i EAJS Executive Committe i Oxford Centre for Postgraduate Studies, Oxford University.

Direktør Erland Kolding Nielsen deltog 3. aug. 1996 i LIBER Executive Board i Bern; holdt 17. aug. 1996 festtalen om Den lokale kulturarv i moderne perspektiv ved Maribo Stiftsbiblioteks 200 års jubilæum; deltog 26.-29. sept. 1996 i 10th Meeting of the Conference of European National Librarians i Lissabon; valgtes 25. sept. 1996 til formand for Sammenslutningen af Danmarks Forskningsbiblioteker og næstformand i Danmarks Forskningsbiblioteksforening.

Universitetslektor, cand.mag. Niels Krabbe er 1. sept. 1996 ansat som førstebibliotekar ved Musikafdelingen.

Forskningschef, dr.phil. John T. Lauridsen deltog i radioprogrammet på $\mathrm{P} 1$ om Besattelsestidsarven aug. 1996.

Forskningsbibliotekar Bent Lerbæk Pedersen deltog 11.-15. sept. i European Association of Sinological Librarians' årlige konference ved Sinologisches Seminar der Universität Heidelberg.

Cand.mag. Ole Meyer er 1. aug. 1996-31. juli 1997 ansat som forskningsstipendiat i Forskningsafdelingen; deltog 9.-11. sept. 1996 i The Second ITI International Colloquium on Literary Translation, ved University of East Anglia, Norwich (England), og ledede en workshop om oversættelser af Dantes Guddommelige Komedie Translating The Divine Comedy Today - a comparison of passages from 20th century translations into English, German, French and the Scandinavian languages.

Cand.scient.pol. Birthe Thykier Møller er 1. aug. 1996 - 31. juli 1997 ansat som forskningsbibliotekar i statskundskab/politologi i Universitetsbiblioteksafdelingen.

Bibliotekar Klaus Møllerhøj deltog 1.-6. sept. 1996 i Perugia i IAML's årlige konference.

Overarkivar, dr.phil. Birgitte Possing deltog 8.-11. aug. 1996 i det 5. nordiske kvindehistorikermøde i Hønefoss, Norge, og holdt foredrag om metoder $i$ den videnskabelige, historiske biografi; foretog 27. sept. - 12. okt. 1996 en forskningsrejse til Paris.

Driftschef Leo Poulsen er genvalgt til hovedbestyrelsen i Danmarks Forskningsbiblioteksforening; genvalgt til 
bestyrelsen i Foreningen af Medarbejdere ved Danske Forskningsbiblioteker.

Cand. mag. Katrine Prassé er 1. sept. 1996 ansat som forskningsbibliotekar i germansk sprog og litteratur i Informations- og Dokumentationsafdelingen.

Fg. afdelingsleder, mag.art. Stig T. Rasmussen er pr. 1. sept. 1996 udnævnt til førstebibliotekar og leder af Orientalsk og Judaistisk Afdeling.

Direktør Erland Kolding Nielsen og førstebibliotekarerne Annika Salomonsen og Stig T. Rasmussen deltog 26.-31. aug. i IFLA's 62. generalkonference i Beijing.

Overbibliotekarerne Steen Bille Larsen og Karl Krarup og førstebibliotekar Charlotte Rohde deltog 15. sept. 1996 i åbningen af den 6 . internationale Arkitektur Biennale i Venedig med præsentation af Det kongelige Biblioteks Havnefrontsprojekt.

Direktør Erland Kolding Nielsen, overbibliotekarerne Steen Bille Larsen og Karl Krarup, førstebibliotekarerne Grethe Jacobsen, Bodil Koch, sagsbehandler Julie Fryd Johansen, fuldmægtigene Birgit Berg og Jytte Christensen, forskningsbibliotekar Anne-Mette Kirkeby, cand.mag. Erik Schwägermann, driftschef Leo Poulsen, afdelingsbibliotekarerne Anne-Marie Smith og Lene Bundgaard, bibliotekarerne Gurli Jacobsen,
Therese Høeg-Jacobsen og Vibeke Loch Nielsen og overassistenterne Kurt Andersen og Sten Tulinius deltog 24.-25. sept. 1996 i Danmarks Forskningsbiblioteksforenings årsmøde i Middelfart med titlen Uddannelse, uddannelsespolitik og kompetenceudvikling.

Førstebibliotekar Ingrid Fischer Jonge, forskningsbibliotekar Henrik Dupont, afdelingsbibliotekar Inger Lise Nørregaard og bibliotekarerne Annie Lenschau Teglers, Lizzi Schwenger, Inger Uldal og Susan Vejlsgaard deltog 22.-27. sept. 1996 i Groupe des Cartotécaires de LIBERs 10. konference på Staatsbibliothek zu Berlin med emnet Planning the New Map Library. Henrik Dupont afgik, og Inger Uldal tiltrådte som National Corresponding Member. Susan Vejlsgaard blev genvalgt som medlem af bestyrelsen og som formand for The Working Group for the Education in Mapcuratorship. Henrik Dupont holdt et foredrag med titlen The Map Department in the New Royal Library.

Førstebibliotekar Ingrid Fischer Jonge og forskningsbibliotekarerne Bruno Svindborg og Edna Basud Thorsen deltog 28. sept.-5. okt. 1996 i studierejse til London som led i Forskningsbibliotekar- og Dokumentalistuddannelsen ved Danmarks Biblioteksskole. 